FACULdADE DE CIÊNCIAS ECONÔ MICAS DA UFRGS

MACROECONOMIA DO BRASIL PÓS-1994 LUIZ CARLOS BRESSER-PEREIRA

DESENVOLVIMENTO ECONOMMICO, PREFERÊNCIA PELA LIQUIDEZ E ACESSO BANCÁRIO: UM ESTUDO DE CASO DAS MESORREGIÓES DE MINAS GERAIS

MARCO CROCCO, CLAUDIO BARRA DE CASTRO, ANDERSON CAVALCANTE E VANESSA DA COSTA VAL

FRIEDMAN E O MONETARISMO: A VELHA TEORIA QUANTITATIVA DA MOEDA E A MODERNA ESCOLA MONETARISTA

GENTIL CORAZZAE RODRIGO L. KREMER

BOLLHAS RACIONAIS, CICLO DE PREÇOS DE ATIVOS E RACIONALIDADE LIMITADA: UMA AVALIACAOO CRITICA DOS MODELOS NEOCLÁSSICOS DE BOLHAS ESPECULATIVAS JOSÉ LUIS OREIRO

VULNERABILITY INDICATORS OF THE TWIN CRISES: THE EAST ASIAN EPISODE

TITO BELCHIOR SILVA MOREIRA

IMPACTOS POTENCIAIS DA NEGOCIAÇÃO DA ALCA SOBRE OS INVESTIMENTOS EXTERNOS EM SERVIÇOS PROFISSIONAIS NO BRASIL

MICHEL ALEXANDRE, OTAVIANO CANUTO E GILBERTO TADEU LIMA

TEORIA MARXISTA DO VALOR: UMA INTRODUÇẢO ALFREDO SAAD FILHO

UM ESTUDO EMPIRICO DOS CICLOS POLITICO. ECONOOMICOS NO BRASIL

ATHOS PRATES DA SILVEIRA PREUSSLER E MARCELO SAVINO PORTUGAL

RELENDO CHANDLER, WILLIAMSON E NORTH PARA ENTENDER O PROCESSO DE FORMACĀO DAS ESTRADAS DE FERRO NO BRASIL

JEFFERSON ANDRONIO RAMUNDO STADUTO

WEIMAR FREIRE DA ROCHA IR. E CLAIITON ATAIDES DE FREITAS

MATRIZ DE INSUMO-PRODUTO PARA A ECONOMIA TURISTICA BRASILEIRA: CONSTRUCCÃO E ANÁLISE DAS RELAÇÓES INTERSETORIAIS

FRANCISCO CASIMIRO FILHO E JOAQUIM JOSÉ MARTINS GUILHOTO

SEÇĀO ESPECIAL: AVALIAÇŌES INICIAIS DA POLITTICA ECONÓMICA DO GOVERNO LULA

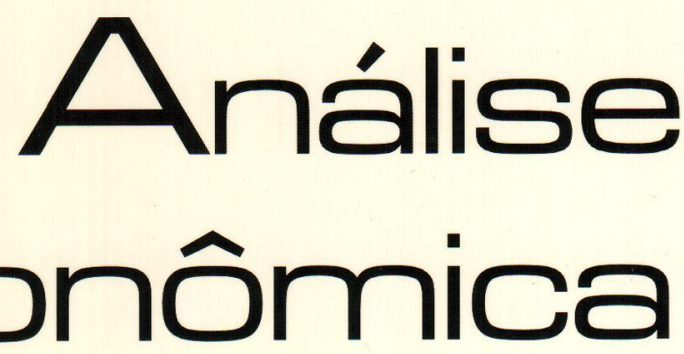


Universidade Federal do Rio Grande do Sul

Reitora: Profa. Wrana Maria Panizzi

Faculdade de Ciencias EConómicas

Diretora: Prof Pedro César Dutra Fonseca

Centro de Estudos e Pesquisas Economicas

Diretor: Prof. Gentil Corazza

Departamento de Ciéncias económicas

Chiefe: Prof. Ricardo Dathein

Curso de Pós. Graduação em Economia

Coordenador: Prof. Eduardo Pontual Ribeiro

Programa de Pós-Graduação em Desenvolvimento Rural

Coordenador: Prof. jalcione Almeida

CONSElHo EDITORIAL:

Carlos G. A. Mielitz Netto (UFRGS), Eduardo A. Maldonado Filho (UFRGS), Eduardo P. Ribeiro (UFRGS), Eleutério F. S. Prado (USP), Eugênio Lagemann (UFRGS), Fernando Cardim de Carvalho (UFRJ), Fernando Ferrari Filho (UFRGS), Fernando de Holanda Barbosa (FGV/RJ), Flávio Vasconcellos Comim (UFRGS), Gentil Corazza (UFRGS), Giácomo Balbinotto Netto (UFRGS), Gustavo Franco (PUC/RJ), Jan A. Kregel (UNCTAD), João Rogério Sanson (UFSC), Joaquim Pinto de Andrade (UnB), Jorge Paulo Araújo (UFRGS), Marcelo S. Portugal (UFRGS), Maria Alice Lahorgue (UFRGS), Paul Davidson (University of Tennessee), Paulo D. Waquil (UFRGS), Pedro C. D. Fonseca (UFRGS), Philip Arestis (Levy Economics Institut of Bard College), Roberto C. de Moraes (UFRGS), Ronald Otto Hillbrecht (UFRGS), Sabino da Silva Porto Jr. (UFRGS), Stefano Florissi (UFRGS) e Werner Baer (University of Illinois at UrbanaChampaign).

COMISSÃO EDITORIAL:

Eduardo Augusto Maldonado Filho, Fernando Ferrari Filho, Gentil Corazza, Marcelo Savino Portugal, Paulo Dabdab Waquil e Roberto Camps Moraes.

EDIroR: Prof. Fernando Ferrari Filho

Editor Adunnio: Prof. Gentil Corazza

SECRETÁrla: Clarissa Roncato Baldim

REVISÁO DE TEXTOS: Vanete Ricacheski

EDITORaÇão Eletrónica: Vanessa Hoffmann de Quadros

Fundador: Prof Antônio Carlos Santos Rosa

Os materiais publicados na revista Análise Econômica são da exclusiva responsabilidade dos autores. É permitida a reprodução total ou parcial dos trabalhos, desde que seja citada a fonte. Aceita-se permuta com revistas congêneres. Aceitam-se, também, livros para divulgação, elaboraçāo de resenhas e recensōes Toda correspondência, material para publicaçāo (vide normas na terceira capa), assinaturas e permutas devem ser dirigidos ao seguinte destinatário:

Análise Econômico

PROF FERNANDO FERRARI FILHO Revisła Análise Econômica - Av. João Pessoa, 52 CEP 90040-000 PORTO ALEGRE - RS, BRASL Telefones: (051) 316-3513 - Fax: (051) 316-3990 E-mail: rae@ufrgs.br

Ano 21, $n^{\circ} 39$, março, 2003 - Porto Alegre

Faculdade de Ciências Econômicas, UFRGS, 2003

Periodicidade semestral, março e setembro.

Tiragem: 500 exemplares

1. Teoria Econômica - Desenvolvimento Regional.

Economia Agrícola - Pesquisa Teórica e Aplicada -

Periódicos. I. Brasil

Faculdade de Ciências Econômicas,

Universidade Federal do Rio Grande do Sul 


\section{A estabilidade da política econômica ante a incerteza do processo de crescimento: até onde pode ir a ortodoxia?}

Octavio A. C. Conceição*

Em nossa história recente, raros foram os momentos que registraram, com tanta veemência, a esperança, clamor e desejo de mudança, como a eleição de 2002 para Presidente da República. A expectativa de um novo ciclo político, na dimensão histórica inaugurada com a Era Vargas, suscitou pressões crescentes sobre a nova equipe dirigente no sentido de fazê-la resolver, rápida e definitivamente, os já clássicos problemas que sempre afligiram a população brasileira. Em outras palavras, o forte apelo popular da candidatura Lula criou expectativas de que sua eleição seria a única forma viável para resolver, no curto prazo e simultaneamente, os problemas do desemprego, da fome, da miséria, da queda do salário real, da inflação e, ao mesmo tempo, impor ao País uma nova trajetória, duradoura e auto-sustentada, de crescimento econômico. É evidente que, por mais legítimas e justas que sejam tais reivindicações, os limites da própria condução da política econômica esbarram na impossibilidade prática, e também teórica, em atacar com êxito todas essas frentes. A política econômica impõe restrições que exigem da parte do governante opções, escolhas e estratégias de ação, que inevitavelmente explicitarāo a marca e a forma de seu respectivo governo. E aí está o maior desafio: materializar a marca de sua governabilidade, sem se afastar das principais propostas de seu programa de Governo.

A série de turbulências que vêm abalando a economia brasileira - acentuadas pós-1999, quando foi abandonado o regime de bandas cambiais fixas - impõe continuamente restrições à política econômica, que, se não forem adequadamente administradas, poderão, em curto espaço de tempo, permitir o retorno da indexação generalizada e da inflação. Tal possibilidade, nos primeiros meses do Governo Lula, foi bem menos longínqua e bem mais provável do que faziam crer os defensores do Plano Real, que apregoavam inad-

\footnotetext{
- Economista da FEE, Professor Adjunto da UFRGS. E-mail: octavio@fee.tche.br.

Este artigo integra um projeto de pesquisa que contou com o apoio financeiro da FAPERGS.
} 
vertida e entusiasticamente a consolidação da "estabilização à brasileira".

A consolidação de um processo de estabilização requer empenho e continuidade. Isso implica afirmar que seu êxito somente será alcançado quando se conseguir construir um ambiente institucional capaz de suportar conviver, em relativa "harmonia", com regras estáveis, que, aí sim, possam vir a assegurar trajetórias estáveis e duradouras de crescimento econômico.

A gestão FHC em seus dois mandatos seguiu trajetórias distintas, que, na atualidade, podem comprometer a ainda frágil constituição de um ambiente estável para o crescimento. Explicando melhor: o período de 1994 até 1998 foi caracterizado pela manutenção da taxa de câmbio fixa, permitindo alguma variação dentro das bandas. Sob tais condicionantes, a economia foi lentamente adequando-se a um regime de estabilidade cambial e dos níveis de preços domésticos, de maneira tal que foi possível controlar eficazmente a memória inflacionária. É por demais sabido o custo desta medida: altas taxas de juros, recessão "induzida", déficits comerciais, atração de capitais voláteis externos e crescimento acelerado da dívida pública interna. A opção entre o controle da inflação ou a retomada do processo de crescimento econômico pendeu necessariamente para o lado do primeiro, sugerindo que a contenção do processo inflacionário era condição necessária, mas não suficiente, para se alcançar a segunda meta. O segundo mandato de FHC estabeleceu logo no seu início a ruptura com o padrão cambial então vigente, fazendo crer que a desvalorização cambial seria a única e mais segura forma de permitir alguma retomada do crescimento, puxado pelo crescimento das exportaçōes. Acreditava-se, na época, que a consolidação da estabilidade dos preços suportaria tal mecanismo sem se transformar em novos movimentos inerciais.

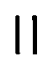

A reiterada reivindicação de solução de enormes e complexos problemas que se avolumaram ao longo dos anos 90 e se agravaram substancialmente em 2002 face à conjuntura vigente, tanto no front externo, quanto interno, em razão de expectativas eleitorais, tem esbarrado em uma única solução. Apenas a retomada do processo de crescimento econômico é capaz de atacar e resolver simultaneamente os graves problemas que afligem o país. Tal propo- 
sição, além de vaga e genérica, estabelece uma relação de causalidade nem sempre válida. Não é automática, nem imediata, a existência de um trade off entre taxa de desemprego e crescimento econômico, como reivindica a tradiçāo teórica advinda da discussão da inflação a partir da curva da Phillips. A redução da taxa de desemprego, além de afetar o mercado de trabalho de maneira lenta e gradual, deve ser acompanhada de políticas compensatórias capazes de neutralizar o impacto do desemprego tecnológico, advindo de novas formas de processo de trabalho gestadas na adoção dos novos paradigmas tecnológicos à Dosi, Freeman e Fabiani (1994). Já o crescimento econômico é um processo que deve estar enraizado (embedded) social, econômica e tecnologicamente, cuja diretriz envolve certas estratégias de concorrência e competitividade e um complexo elenco de novas oportunidades (windows of opportunity), conforme Carlota Perez (1989).

Em outros termos, desatar o nó que impede a economia brasileira de retomar uma trajetória de crescimento, interrompida em meados dos anos 70, implica muito mais do que um cenário de política econômica favorável e estimulante ao investimento produtivo. Implica também a definição de um novo perfil de inserção internacional, em que o País passe a ser visto como atrativo ao retorno do capital; passa por uma profunda reformulação financeira, capaz de garantir as transferências de aplicações financeiras para o circuito da produção, e sem sobressaltos; passa por uma reformulação do aparelho de Estado, cujo papel de financiador-empresário seja substituído por parceiro-indutor de inovatividade e competitividade; e passa pela confiança ou credibilidade dos agentes econômicos na construção das novas trajetórias de crescimento (no nivel da firma), capazes de viabilizar os retornos previstos pela eficiência marginal do capital.

Ou seja, crescimento econômico, antes de se constituir em objeto de "decisão" pelas autoridades governamentais, requer estratégias que impliquem empenho e continuidade, devendo processarse em um ambiente mais micro do que propriamente macroeconômico. O que a política econômica deve e/ou pode fazer é criar condiçōes à formaçāo de um ambiente institucional favorável à articulação de uma compatível trajetória auto-sustentada de crescimento. Crescimento deve necessariamente estar embedded nas decisões e estratégias adotadas pelas firmas, a partir das expectativas dos próprios agentes econômicos. Não é, portanto, um proces- 
so automático, a ser "orientado" pelo Estado, como, inadvertidamente, se possa pensar a partir da experiência vivida pelo processo de substituição de importaçōes no Brasil.

A complexa e intrincada relação entre o processo de estabilização e o de crescimento econômico - que não necessariamente implica desenvolvimento - não pode ser associada a um único processo de natureza linear e direta, sugerindo que um decorra do outro. Como já se argumentou em outros trabalhos (Conceição, 1999 e 2003), ambos têm raízes e naturezas distintas ${ }^{1}$, embora possa se afirmar que o primeiro é condição necessária, mas não suficiente, para a ocorrência do segundo.

A hipótese central deste artigo é que a estabilidade, assim como o processo de crescimento econômico, tem raízes institucionais. Em outros termos, é o ambiente institucional, construído a partir de mudanças nas regras do jogo, nos hábitos dos agentes econômicos e nas estratégias de decisão, que levam a comportamentos rotinizados, que constituem, ao longo do tempo, trajetórias mais ou menos definidas, que podem vir a lograr condições à progressão do crescimento econômico. A consolidação de um processo de estabilização econômica, que caracterizou boa parte dos anos 90 até hoje, não é tarefa fácil e exige empenho e continuidade, sem implicar necessariamente crescimento. É fundamental que se materialize, no bojo do ambiente de decisão das firmas, em regras compatíveis com as mudanças institucionais, orientadas pela "nova trajetória" definida pela estabilização. Como argumenta Castro (1998), o sucesso da estabilização decorre da ruptura com as convenções de "crescimento-com-inflação", que caracterizaram nossa industrialização, notadamente a partir dos anos 60 .

Quer se aceite ou não, o Plano Real atuou sobre os fundamentos estruturais da economia. Isto implica reconhecer que crescer, hoje, não mais se associa às "convenções" de crescimento-com-inflação. A economia brasileira - e a nova ordem mundial - estão a

\footnotetext{
${ }^{1}$ Saliente-se que para o mainstream ambos são passiveis de tratamento semelhante, já que estabilidade e crescimento são processos decorrentes da situação de steady state, que asseguraria trajetórias contínuas e duradouras de ambos os processos.
} 
revelar que se impõem novos condicionantes à questão do crescimento. E os mesmos se inserem em uma perspectiva também microeconômica, tecnológica e financeira, que desafiam o mainstream ortodoxo. A década de 90 , apesar de ter revelado baixas taxas anuais de crescimento, apresentou, do ponto de vista do lado real da economia, profundas transformações na forma de funcionar da economia brasileira. A abertura comercial, a partir do período Collor, trouxe decisivos ingredientes que passaram a fazer parte do cálculo capitalista no processo de tomada de decisão. À feroz exposição ao padrão de concorrência externa, constatou-se que anos de funcionamento em "ambientes microeconômicos" fechados criaram uma espécie de "aversão ao risco" do ponto de vista do comércio exterior. Fizeram-se necessários profundos rearranjos na órbita produtiva - leia-se organizacional, administrativa e tecnológica - de forma a enfrentar nossa, até então, péssima exposição ao padrão competitivo internacional. Ganhos cambiais espúrios, herdados do regime de altas taxas inflacionárias, criaram uma falsa ilusão de nossa precária competitividade. $\mathrm{O}$ ajuste, doloroso, era profundamente necessário para que a economia pudesse contar efetivamente com novas frentes de crescimento a serem semeadas" no plano externo. Passou a ser necessária a construção de ganhos sistêmicos em competitividade e em produtividade para se desafiar a necessária inserçāo no novo paradigma.

Isto, entretanto, não era suficiente. As reformas institucionais são elementos centrais e decisivos à definição de novas trajetórias capazes de assegurar crescimento econômico, avanço tecnológico e diminuição das desigualdades. Tais reformas, apesar de fundamentais, não serão feitas sem sobressaltos, conflitos de interesses, avanços e recuos e negociaçōes políticas. Entretanto, e de forma irreversível, o resultado final do que for implementado balizará a configuração da "nova" estrutura social, política, institucional e tecnológica sobre a qual se desenrolará a almejada trajetória de crescimento econômico. O êxito ou fracasso do referido processo dependerá do acerto ou equívoco das mudanças em curso, que passam necessariamente pela inserção no padrão de desenvolvimento tecnológico vigente, pela incorporação na matriz produtiva nacional da inovação tecnológica, pela adoção de um padrão de gestão empresarial das empresas atrelado à busca de eficiência, competitividade e produtividade, pela redefinição do papel do Estado como ente comprometido com o "avanço" tecnológico e diminuição das desigualdades sociais. 
Vale dizer, o aprofundamento das reformas (previdenciária, fiscal, trabalhista, etc.) afetará inevitavelmente os fundamentos estruturais da economia brasileira, já que desde o Plano Real, direta ou indiretamente, vêm-se modificando todas as formas institucionais de estrutura da economia brasileira. Encontra-se em gestação, mas em um estágio preliminar e incipiente, a potencial constituição de uma nova regulação da economia nacional. A reinserção externa que a política econômica persegue, não é por si só garantia de crescimento algum, mas reveladora das profundas e irreversíveis transformações na relação com o exterior. Entretanto, desde a implementação do Plano Real até os dias de hoje, continua faltando ao País uma estratégia interna para o crescimento, que definiria um novo papel do Estado, da relação entre trabalhadores e capitalistas, da função do capital externo e do capital financeiro nacional na conformação institucional que se seguirá, etc. Enquanto isso não ocorrer, permaneceremos em compasso de espera por uma "retomada" do processo de crescimento econômico.

\section{IV}

Todos esses aspectos revelam que atravessamos um processo de rupturas e reconstruções, características da transição de um velho para um novo (ainda que incipiente) processo de crescimento, que, apesar de se apresentar quantitativamente como um incremento na relação produto-capital, reveste-se , de país para país, de características bastante distintas. Tal assertiva, apesar de parecer óbvia, reflete um enfoque alternativo, oriundo da interpretação neoschumpeteriana. Isto porque as firmas, tecnologias e instituições, que sempre estiveram ausentes do core das explicações sobre crescimento econômico dos economistas ortodoxos, devem hoje assumir função central no detalhamento teórico do referido processo ${ }^{2}$. Sob essa perspectiva, desenvolvimento é um processo inerentemente desordenado e doloroso, em que, não raras vezes, os trabalhadores ou administradores especializados são desvalorizados, perdendo seus empregos e rendas, e novas especialidades são recompensadas,

\footnotetext{
${ }^{2}$ Segundo Dosi, Freeman e Fabiani (1994, p. 2): “(...) the interpretation of growth and development requires a detailed understanding of how technological innovations are generated and diffused; of the incentives structure facing economic actors; of the internal organization, competences and strategies of business firms; of the institutions in which agents are embedded and which constrain and guide both microeconomic coordination and change."
} 
causando transtornos e problemas políticos. Há disputa entre perdedores e ganhadores no desenho do novo processo para ver quem se beneficia ou perde com o crescimento (Zysman, 1994, p. 257).

As teorias de crescimento, de natureza institucionalista, enfatizam que as trajetórias de crescimento são criadas historicamente, a partir do desenvolvimento das especificidades nacionais institucionalmente inventadas ou enraizadas. Daí se infere que há várias formas de economias de mercado, onde os mesmos são diferentes, definindo também vários tipos de capitalismo ${ }^{3}$. Em tal abordagem, os mercados, embedded nas instituições políticas e sociais, não são nada mais que criações ou invenções humanas de seus governos e da política. Eles também não operam, nem funcionam fora das regras e das instituições que os estabelecem e os estruturam. Daí, a conclusão que "... there are multiple market capitalisms, and in a global economy international competition among members must be understood as an interplay of these various national market systems." (Zysman, 1994, p. 243). Como as instituições estão enraizadas nacional e historicamente pode-se designar tal abordagem como uma espécie de "institucionalismo histórico", sem deixar de referir que levanta problemas e propōe soluções considerando aspectos relacionados ao microeconomic-based institutionalism ${ }^{4}$. Neste sentido, diferentes conformações históricas e institucionais desenham, nos diversos contextos regionais, os sistemas nacionais de inovação, que distinguem as trajetórias tecnológicas. Por isto, institucionalismo e evolucionismo são fenômenos impossíveis de serem compreendidos de maneira desvinculada. Tais conclusões requalificam o debate sobre formas alternativas de crescimento, colocando o mercado e suas especificidades nacionais como fator condicionante a tal objetivo. Entretanto, as instituições devem ser entendidas não como um princípio regulador e racionalizador de decisōes ótimas, mas como produto de interações, estratégias, decisões frente à incerteza que repercutem, favoravelmente ou não, através da atuação de toda uma rede institucional, que the assegura sustentabilidade. As estru-

\footnotetext{
${ }^{3}$ Minsky (1996) faz menção à existência de 57 tipos de capitalismo. Hodgson (1996) também se ocupa da variedade de conformaçōes históricas.

${ }^{4}$ Sob essa ótica: "The institutional approach begins with the observation that markets, embedded in political and social institutions, are the creation of government and politics (Polanyi, 1944). Indeed all economic interchange takes place within institutions and groups. There is not a single market system that is distorted in various ways by institutions and politics in the several contexts. (...) National stories do not stand alone and cannot be examined in isolation." (Zysman, 1994, p. 244).
} 
turas institucionais nacionais são resultantes do processo histórico de desenvolvimento industrial e da modernização política, o que está diretamente associado à argumentação evolucionária das trajetórias tecnológicas, que levam em conta fatores essenciais como o processo de difusão da informação e o de geração de novas idéias 5 .

Ou seja, as instituições não são neutras e podem proporcionar explicações sobre trajetórias específicas ou equilíbrio, delas decorrentes. Assim, uma dada estrutura política e institucional induz à formação de uma lógica de mercado, que orienta e dirige a trajetória de crescimento. O que se objetiva argumentar com essas notas é que qualquer trajetória de crescimento econômico que a economia brasileira venha a apresentar, seu percurso será mais ou menos penoso em função das escolhas e estratégias decididas no presente. Nesse sentido, a política econômica adotada pelo atual governo será avaliadora de quão exitosa ou fracassada será nossa caminhada, mas jamais, isoladamente, poderá nos levar à construção desse caminho. Tal escolha passará pelo arcabouço formado pelas instituições, que lhe darão sustentação, e que, atualmente, estão em um processo de profundas mudanças.

\section{Referências bibliográficas}

CASTRO, A. B. (1997). Renegade Development: Rise and Demise of State-Led Development in Brazil. Rio de Janeiro, nov. In: SEMINÁRIO INTERNACIONAL INSTITUIÇŌES EDESENVOLVIMENTO ECONÔMICO. Anais...

CASTRO, A. B. (1999). "O lado real do Real: o debate e algumas surpresas". In: MAGALHÃES, J. P. A., MINEIRO, A. S., ELIAS, L. A (Org.) Vinte anos de política econômica. Rio de Janeiro, Contraponto/Corecon. Edição Comemorativa do Instituto dos Economistas do Rio de Janeiro.

CONCEIÇĀO, Octavio A.C. (1999). "Desvalorização do Real: a agonia de uma estabilização inacabada". Indicadores Econômicos FEE, Porto Alegre, FEE, v. 27, n 1. CONCEIÇĀO, Octavio A.C. (2003). "Continuidade, governabilidade e mudan-

\footnotetext{
${ }^{5}$ Segundo Zysman (1994, p. 260): "These arguments have distinct intellectual starting points. But they have in common the notion that it is not just an accumulation of capital investments that drives growth. Rather growth is a function of the accumulation of technological bets, as we shall see, can only be understood in a national institutional environment." Mais ainda: "Technology, like market processes, is not disembodied. It develops in communities; it has local roots. The processes of learning that drive its development are shaped by the community and institutional structure, and consequently the technological trajectories can only be defined in reference to particular societies." (Zysman, 1994, p. 261)
} 
ça: desafios de uma política de crescimento econômico'. Carta de Conjuntura FEE, Porto Alegre, FEE. Ano 12, n. 6, jun.

COUTINHO, Luciano e FERRAZ, João Carlos (Coord.) (1994). Estudo da Competitividade da Indústria Brasileira. 2 ed. Campinas, Edit. Unicamp.

DOSI, Giovanni, FREEMAN, Christopher and FABIANI, Silvia (1994). "The Process of Economic Development: Introducing Some Stylized Facts and Theories on Technologies, Firms and Institutions". Industrial and Corporate Change. V. 3, n. 1, p. I-45.

DOSI, G. EORSENIGO, L. (1988). "Coordination and transformation: on overview of structures, behaviours and change in evolutionary environments": In: DOSI, G. et alii (eds.). Technical Change and Economic Theory. London: Pinter Publishers. FREEMAN, C. \& PEREZ, C. (1988). "Structural crises of adjustment business, cycles and investment behaviour". In: DOSI, G. et alii (eds.) Technical Change and Economic Theory. London, Pinter Publishers.

HODGSON, Geoffrey M. (1996). "Varieties of capitalism and varieties of economic theory". Review of International Political Economy. v. 3, n. 3, p. 380-433, autumn.

MINSKY, H. (1996). "Uncertainty and the Institutional Structure of Capitalist Economics". Journal of Economics Issues. v. XXX, n. 2, p. 357-368, June.

ZYSMAN, John. (1994). "How Institutions Create Historically Rooted Trajectories of Growth". Industrial and Corporate Change. v. 3, n. 1, p. 243-283. 